\title{
Virtual autopsy to assess sacral anatomy: Conditions for a minimal invasive approach to the spinal canal through the hiatus sacralis
}

\author{
Andrea Bodmer, Steffen Ross ${ }^{1}$, Andreas Raabe, Jürgen Beck, Christian T. Ulrich, Philippe Schucht \\ Department of Neurosurgery, Inselspital, Bern University Hospital, Freiburgstrasse, Bern, 'Department of Radiology, Spital Männedorf, Asylstrasse, Männedorf, \\ Switzerland \\ E-mail: Andrea Bodmer - andreabodmer@yahoo.com; Steffen Ross - steffen.ross@me.com; Andreas Raabe - andreas.raabe@insel.ch; \\ Jürgen Beck - juergen.beck@insel.ch; Christian T. Ulrich - christian.ulrich@insel.ch; *Philippe Schucht - philippe.schucht@insel.ch \\ *Corresponding author
}

Received: 17 August $17 \quad$ Accepted: 19 September $17 \quad$ Published: 06 December 17

\begin{abstract}
Background: Despite multiple advantages of minimally invasive techniques in spinal surgery, the currently used approaches may lead to postoperative pain and spinal instability. As a natural orifice, the hiatus sacralis offers a nontransmuscular alternative entry point for endoscopic approaches. In this study, we collected data about the complex anatomical conditions of the sacral canal as a basis for the development of a sacral endoscope.
\end{abstract}

Methods: We retrospectively evaluated 192 postmortem human cadaveric specimens with computed tomography (CT). The anatomical conditions of the sacrum and lumbar spine were analyzed, including assessment of the lateral and anteroposterior diameters, measurement of the cross-sectional area of the sacral canal at the lumbosacral transition, hiatus sacralis, and the narrowest point of the sacral canal.

Results: The narrowest anteroposterior diameter was $>2.3 \mathrm{~mm}$ in $95 \%$ of the cases; the width was $>13 \mathrm{~mm}$ in $95 \%$ of the cases. The narrowest point was located at the hiatus in $72 \%$ of the cases. The angle of sacral kyphosis was less than $30^{\circ}$ and less than $50^{\circ}$ in lumbar lordosis in $95 \%$ of the cases. A length shorter than $288 \mathrm{~mm}$ was measured in $95 \%$ of the cases. Anatomical conditions in male and female sacra were comparable.

Conclusions: The narrow anteroposterior diameter is the key limiting feature for using the canalis sacralis as a natural entry point into the spinal canal. Sacroscopy will require endoscopes with a flattened shape, with parallel arrangement of instruments and flexibility to accommodate the varied dorsal and ventral curvatures.

Key Words: Chronic lumbar pain, endoscopy, minimally invasive surgery, sacral anatomy, sacroscopy, spinal surgery

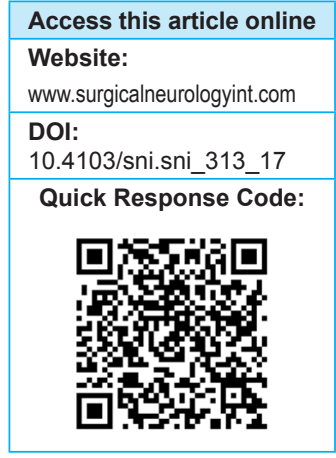

This is an open access article distributed under the terms of the Creative Commons Attribution-NonCommercial-ShareAlike 3.0 License, which allows others to remix, tweak, and build upon the work non-commercially, as long as the author is credited and the new creations are licensed under the identical terms.

For reprints contact: reprints@medknow.com

How to cite this article: Bodmer A, Ross S, Raabe A, Beck J, Ulrich CT, Schucht P.Virtual autopsy to assess sacral anatomy: Conditions for a minimal invasive approach to the spinal canal through the hiatus sacralis. Surg Neurol Int 2017;8:290.

http://surgicalneurologyint.com/Virtual-autopsy-to-assess-sacral-anatomy:-Conditions-for-a-minimal-invasive-approach-to-the-spinal-canal-through-the-hiatus-sacralis/ 


\section{INTRODUCTION}

Epiduroscopic spinal surgery as a minimally invasive procedure was first reported in the 1930s when Burman used arthroscopic equipment for the assessment of spinal pathology. ${ }^{[3]}$ The first use of small flexible fiberoptic scopes was published by Shimoji et al. in 1991.[9]

In theory, minimally invasive (MIS) endoscopic techniques offer shorter operating times, short rehabilitation period, and reduced tissue trauma compared with routine open approaches. ${ }^{[6,13]}$ Despite these advantages, epidural scarring, spinal instability, and operation-induced disorders of the innervation of the back muscles are common complications, often leading to chronic and recurrent back pain. ${ }^{[4,5,7,10,12]}$ Alternatively, the hiatus sacralis, localized immediately below a thin layer of skin, offers a natural entry point and superficial, potential easier access to the spinal canal while limiting potential muscle damage. Notably, in this series, exploratory use of sacroscopy was aborted in $10 \%$ of the cases due to anatomical limitations of the hiatus sacralis. ${ }^{[8]}$ Further investigations of the anatomical conditions of the sacral canal are warranted to develop a viable endoscopic approach.

\section{MATERIALS AND METHODS}

Sacral and lumbar spinal anatomical measurements were based on computed tomography (CT) data sets from the Institute of Forensic Medicine associated. Postmortem CT was carried out as a part of the routine forensic investigation, known as "Virtual Autopsy". This included a noninvasive autopsy performed on a human body (developed in Switzerland). We enrolled 192 cases, 18-89 years of age, in whom a CT scan of the abdomen had been performed for forensic appraisal (2009-2010) [Table 1]. Exclusion criteria are shown in Table 2. Imaging was executed in supine position on a 6-row multi-slice CT scanner (Somaton Emotion 6, Siemens Medical Solutions, Erlangen, Germany). Raw data acquisition was performed with the following settings: $130 \mathrm{kV} ; 200 \mathrm{mAs}$; collimation, $6 \times 1 \mathrm{~mm}$ whole body. Image reconstruction was performed at slice thickness $1.25 \mathrm{~mm}$ with an increment of half the slice thickness in soft tissue, and bone-weighted reconstruction kernel. Image review, multiplanar reconstructions (MPR), and measurements were performed on a PACS-workstation (IDS/, Sectra AB). The lateral and anteroposterior (AP) diameters as well as the sectional area of the sacral canal were recorded at the lumbosacral transition, at the hiatus sacralis, and at the level of the narrowest point of the sacral canal defined by human eyes [Figures 1-4]. Length and bending of the spinal canal were measured from the upper rim of the first lumbar vertebral body down to the hiatus sacralis. Bending is described in angle degrees and was measured
Table 1: Age and sex distribution of cases included in the study

\begin{tabular}{lccc}
\hline Age group (years) & Men $(\boldsymbol{n})$ & Women $(\boldsymbol{n})$ & Total $(\boldsymbol{n})$ \\
\hline $18-35$ & 17 & 4 & 21 \\
$36-50$ & 24 & 8 & 32 \\
$51-65$ & 18 & 9 & 27 \\
$>66$ & 12 & 8 & 20 \\
Total & 71 & 29 & 100 \\
\hline
\end{tabular}

Table 2: Criteria and number of cases excluded from the study

\begin{tabular}{lccc}
\hline Criterion for exclusion & Men $(\boldsymbol{n})$ & Women $(\boldsymbol{n})$ & Total $(\boldsymbol{n})$ \\
\hline Poor image quality & 29 & 21 & 50 \\
Incomplete data & 24 & 18 & 42 \\
Total & 53 & 39 & 92 \\
\hline
\end{tabular}

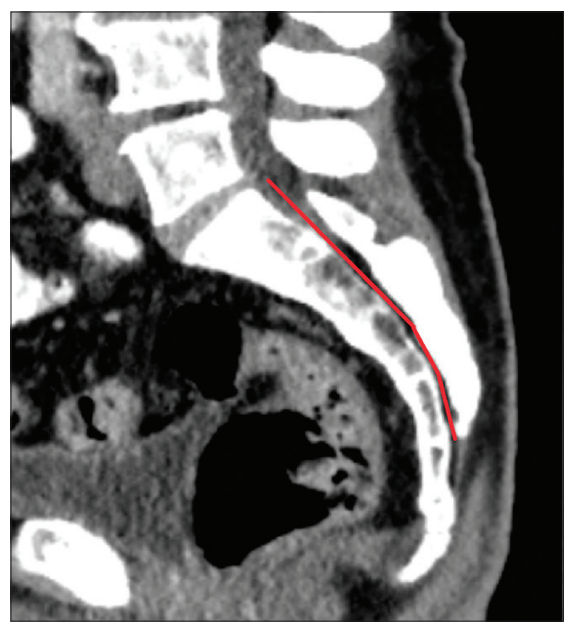

Figure I: Sagittal view of the sacrum. Bending of the sacral and lumbar spine demand flexibility of the endoscope of at least $30^{\circ}$ and $50^{\circ}$ to accommodate the ventral and dorsal curvature, respectively. (Figure kindly provided by the Spital Oberengadin, Samedan)

in the center of the sacral and lumbar canal, indicated as a difference from the straight line $\left(180^{\circ}\right)$ corresponding to kyphosis and lordosis.

\section{RESULTS}

One hundred cases were included in this analysis; 71 were males and 29 were females. Details of age and sex distribution are outlined in Table 1 . As shown in Table 3, the AP diameter was wider than $2.5 \mathrm{~mm}$ in 95\% of the cases, whereupon the narrowest point was found at $5-13 \mathrm{~mm}$ cranial of the hiatus in 28 cases, other 72 cases showed the narrowest point at the hiatus itself.

The narrowest point of the lateral diameter was found cranial of the hiatus sacralis in 46 cases and measured more than $13 \mathrm{~mm}$ in $95 \%$ of the cases. The surface areas 
of the sacral canal ranged $32-147 \mathrm{~mm}^{2}$ and $26-159 \mathrm{~mm}^{2}$ for females and males, respectively.

Regarding the angles of sacral kyphosis and lordosis see Table 4. In 11 cases, the angles were $180^{\circ}$, and therefore, did not show any curvature. Measurements of the length from the upper rim of the first lumbar vertebral body to the hiatus sacralis along the spinal canal varied from 210 to $305 \mathrm{~mm}$; however, $97 \%$ of the cases presented with lengths $<290 \mathrm{~mm}$ [Table 5]. None of the cases showed statistically significant differences in anatomical conditions between male and female sacra.

\section{DISCUSSION}

\section{Measurement of the anteroposterior diameter} In an autopsy specimen study by Witte et al., ${ }^{[11]}$ data from 117 sacra of cases aged 69 years and older were measured

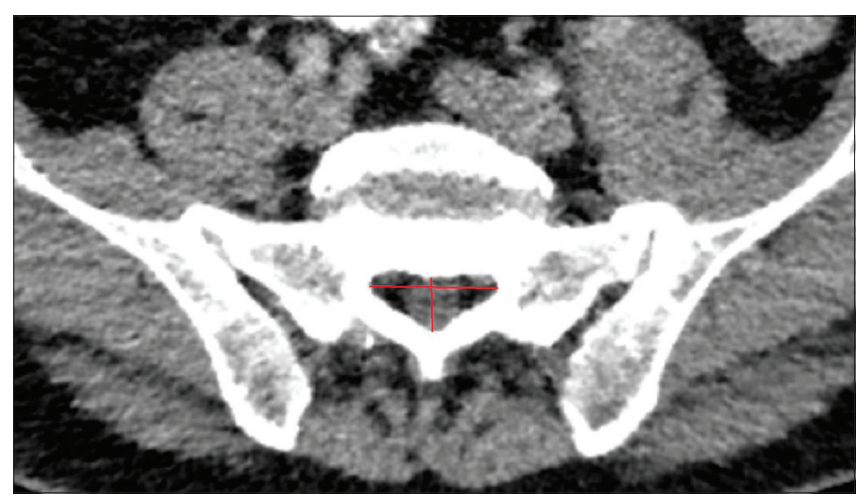

Figure 2: Axial view of the lumbosacral transition. To reach the lumbosacral transition for surgical interventions an endoscope with a minimal length of $290 \mathrm{~mm}$ should be developed to accommodate $95 \%$ of the patients. (Figure kindly provided by the Spital Oberengadin, Samedan) to determine geometric coordinates. They found an average AP diameter of $5 \mathrm{~mm}$ at a $90-\mathrm{mm}$ distance in the caudal direction of the lumbosacral transition. At this point, the minimal AP diameter was $2.45 \mathrm{~mm}$. Data of the location of the absolute narrowest point in the sacral canal were not provided. In this study, we found this to be the hiatus in $72 \%$ of our cases.

\section{Measurement of the lateral diameter}

The lateral diameter in the Witte et al. study measured $14 \mathrm{~mm} \pm 5 \mathrm{~mm}$ at the upper rim of $\mathrm{Sl}$ and $8 \mathrm{~mm} \pm 5 \mathrm{~mm}$ at S4. The distance from the lumbosacral transition to the hiatus sacralis ranged from 85 to $155 \mathrm{~mm}$. They also recorded the degrees of bending of the sacral canal up to $60^{\circ}$. It is yet unclear whether these findings in the geriatric population are applicable to the general population, as degenerative changes might have influenced the dimensions of the sacral canal. Moreover, materials based on autopsy specimens might contain artifacts that jeopardize the conclusions due to manipulation and dissection of the bony structures. To work more precisely and to get closer to the in-vivo status, our measurements were based on CT scans instead of measuring by millimeter grids.

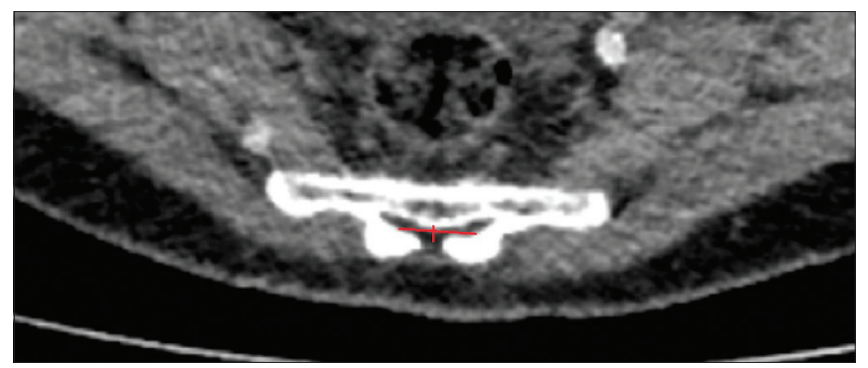

Figure 3: Axial view of the hiatus. The narrowest anteroposterior diameter of the canalis sacralis is located at the hiatus in $72 \%$ of the cases. (Figure kindly provided by the Spital Oberengadin, Samedan)

Table 3: Anteroposterior and lateral diameters; area in the sacral canal

\begin{tabular}{|c|c|c|c|c|c|c|}
\hline Population [\%] & $\begin{array}{l}\text { ap-d [mm] } \\
\text { Hiatus }>x\end{array}$ & $\begin{array}{c}\text { ap-d [mm] } \\
\text { Narrowest point }>x\end{array}$ & $\begin{array}{l}\text { lat-d [mm] } \\
\text { Hiatus }>x\end{array}$ & $\begin{array}{l}\text { lat-d }[\mathrm{mm}] \\
\text { Narrowest point }>x\end{array}$ & $\begin{array}{l}\text { area }\left[\mathrm{mm}^{2}\right] \\
\text { Hiatus }>\mathrm{x}\end{array}$ & $\begin{array}{l}\text { area }\left[\mathrm{mm}^{2}\right] \\
\text { Narrowest point }>\mathrm{x}\end{array}$ \\
\hline $96-100$ & 2.5 & 2 & 13 & 13 & 45 & 30 \\
\hline $91-95$ & 3 & 2.5 & 15 & 14 & 55 & 40 \\
\hline $86-90$ & 3 & 3 & 16 & 14 & 60 & 45 \\
\hline $81-85$ & 3 & 3 & 17 & 16 & 60 & 50 \\
\hline $76-80$ & 3.5 & 3.5 & ns & 16 & 65 & 55 \\
\hline $71-75$ & 3.5 & 3.5 & ns & 16 & ns & 60 \\
\hline
\end{tabular}

ap-d:Antero-posterior diameter, lat-d: Lateral diameter, ns: Not specified, $\mathrm{x}$ : Length in millimeters

Table 4: Curvature of the lumbar and sacral canal of cases included in the study, indicated in angle degrees

\begin{tabular}{lccc}
\hline $\begin{array}{l}\text { Degree of bending } \\
=\text { angle } \boldsymbol{\alpha}\left[^{\circ}\right]\end{array}$ & $\begin{array}{c}\text { deviation from the straight } \\
\text { line }\left(=\mathbf{1 8 0 ^ { \circ }}\right) \text { angle } \boldsymbol{\beta}\left[^{\circ}\right]\end{array}$ & $\begin{array}{c}\text { Population [\%] showing } \\
\text { curvature }<\boldsymbol{\beta} \text {. Lumbar lordosis }\end{array}$ & $\begin{array}{c}\text { Population [\%] showing } \\
\text { curvature < } \boldsymbol{\beta} \text {. Sacral kyphosis }\end{array}$ \\
\hline 130 & 50 & 94 & 100 \\
140 & 40 & 70 & 100 \\
150 & 30 & $<70$ & 95 \\
160 & 20 & $<70$ & 67 \\
\hline
\end{tabular}




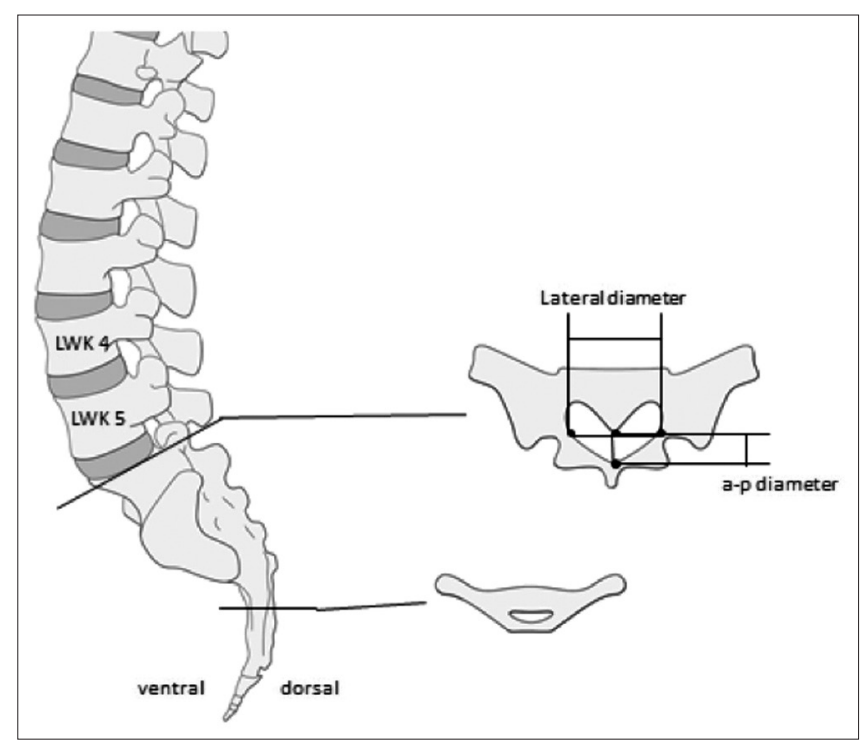

Figure 4: Measurements of the angles and diameters. The lateral and anteroposterior diameters as well as the sectional area were recorded at the lumbosacral transition, at the hiatus sacralis, and at the level of the narrowest point of the sacral canal on 100 CT-datasets

Table 5: Length of the lumbar and sacral canal in cases included in the study

\begin{tabular}{lc}
\hline Population [\%] showing $\mathbf{x}<\mathbf{D}$ & distance D Hiatus-L1 [mm] \\
\hline 96.8 & 290 \\
92.5 & 280 \\
86 & 270 \\
\hline
\end{tabular}

However, our measurements were, as mentioned above, made in the supine position. As anatomy most often is position-dependent, measures of the lumbosacral angle might differ in prone position perioperatively.

Suggested use of flexible endloscope

Based on their findings, Witte et al. suggested the use of a flexible circular-shaped endoscope not exceeding a diameter of $4 \mathrm{~mm}$. Due to their measurement and a trial of an arthroscope in five cadavers, they found that an endoscope of $4 \mathrm{~mm}$ would require surgical enlargement of the sacral canal to obtain access to the spinal canal in at least $20 \%$ of the patients.

Due to our findings of anatomical conditions and to accommodate $95 \%$ of the patients we suggest a flat-shaped endoscope having a vertical height of less than $2.5 \mathrm{~mm}$, a width of less than $13 \mathrm{~mm}$, and a minimal length of $290 \mathrm{~mm}$.

\section{Navigation issues with endoscopy}

Several studies mentioned technical issues regarding navigation of the flexible but instable endoscope (2.5-3 $\mathrm{mm}$ diameter) through the spinal canal. ${ }^{[7,8]}$ Furthermore, mechanical operations proved to be difficult due to the miniscule size of working tools; for example, extraction of greater tissue components was shown to be difficult. ${ }^{[7]}$

Ruetten et al. also reported hemorrhages during mechanical processing, mostly due to surgical detachment of adhesions found in the dorsal epidural space of patients that had been previously operated upon. ${ }^{[7]}$

With respect to the anatomic conditions of the sacral canal and with consideration of the issues mentioned above, we believe the optimal endoscope should have a flat shape with similarly flattened instruments. Such geometry will provide better access to the spinal canal and will improve stability of the endoscope. A flexibility of $50^{\circ}$ in the dorsal direction and $30^{\circ}$ in the ventral direction would lead to better guidance. If in rare cases penetration into the spinal canal is interrupted due to a narrow hiatus sacralis, a simple enlargement of the hiatus by $1-2 \mathrm{~cm}$ in a cauda-cranial direction could be done to overcome the resistance. The dorsomedian connective tissue band fixing the dura mater to the flaval ligaments and narrowing the epidural space in the midline ${ }^{[1,2]}$ predisposes the endoscope to be used in the ventral epidural space.

\section{CONCLUSIONS}

In conclusion, the hiatus sacralis presents a natural orifice for sacroscopy. It also offers an additional site for MIS. Our study delineates the requirement of a future sacral endoscope, as mentioned above. Further technical studies are warranted for the construction of an adequate endoscope.

\section{Financial support and sponsorship}

Nil.

\section{Conflicts of interest}

There are no conflicts of interest.

\section{REFERENCES}

I. Blomberg R. The dorsomedian connective tissue band in the lumbar epidural space of humans: An anatomical study using epiduroscopy in autopsy cases. Anesth Analg 1986;65:747-52.

2. Blomberg RG, Olsson SS. The lumbar epidural space in patients examined with epiduroscopy. Anesth Analg 1989;68:157-60.

3. Burman MS. Myeloscopy or the direct visualization of the spinal cord and its contents. J Bone Joint Surg 1931;13:695-6.

4. Fritsch EW, Heisel J, Rupp S. The failed back surgery syndrome: Reasons, intraoperative findings, and long-term results: A report of 182 operative treatments. Spine 1996;21:626-33.

5. Kotilainen E, Valtonen S. Clinical instability of the lumbar spine after microdiscectomy. Acta Neurochir (Wien) 1993; I 25:120-6.

6. Ruetten S, Komp M, Merk H, Godolias G. Surgical treatment for lumbar lateral recess stenosis with the full-endoscopic interlaminar approach versus conventional microsurgical technique: A prospective, randomized, controlled study. J Neurosurg Spine 2009; 10:476-85.

7. Ruetten S, Meyer O, Godolias G. [Epiduroscopic diagnosis and treatment of epidural adhesions in chronic back pain syndrome of patients with previous 
surgical treatment: First results of 31 interventions]. Z Für Orthop Ihre Grenzgeb 2002;140:17|-5.

8. Ruetten S, Meyer O, Godolias G. Endoscopic surgery of the lumbar epidural space (epiduroscopy): Results of therapeutic intervention in 93 patients. Minim Invasive Neurosurg 2003;46: I-4.

9. Shimoji K, Fujioka H, Onodera M, Hokari T, Fukuda S, Fujiwara N, et al. Observation of spinal canal and cisternae with the newly developed small-diameter, flexible fiberscopes. Anesthesiology 1991;75:341-4.

10. Sihvonen T, Herno A, Paljärvi L, Airaksinen O, Partanen J, Tapaninaho A. Local denervation atrophy of paraspinal muscles in postoperative failed back syndrome. Spine 1993;18:575-81.
II. Witte H, Hellweg S, Witte B, Grifka J. [Epiduroscopy with access via the sacral canal. Some constructional equipment requirements from the anatomic and biomechanical viewpoint]. Biomed Tech (Berl) 1997;42:24-9.

12. Yadav YR, Parihar V, Namdev H, Agarwal M, Bhatele PR. Endoscopic interlaminar management of lumbar disc disease. J Neurol Surg Part Cent Eur Neurosurg 2013;74:77-8I.

13. Yamada H, Yoshida M, Hashizume H, Minamide A, Nakagawa Y, Kawai M, et al. Efficacy of novel minimally invasive surgery using spinal microendoscope for treating extraforaminal stenosis at the lumbosacral junction. J Spinal Disord Tech 2012;25:268-76. 